\title{
FRANZ NEUMANN, O DIREITO E A TEORIA CRÍTICA
}

\author{
JOSÉ RODRIGO RODRIGUEZ
}

We can never be born enough.

E.E. Cummings

Franz Neumann, estudioso do Direito e participante do Instituto de Pesquisas Sociais, tem sido objeto de pelo menos duas diferentes redescobertas intelectuais. A primeira deu-se na esteira da revalorização da obra de Carl Schmitt nos Estados Unidos da América, seguida da reação de diversos teóricos de esquerda para recuperar seus críticos de primeira hora como Franz Neumann e Otto Kirchheimer. ${ }^{1}$ Do outro lado do Atlântico, na Alemanha, Axel Honneth tem sugerido que a discussão da obra desses autores, representantes do assim denominado "círculo externo" do Instituto de Pesquisas Sociais, pode revelar certos "achados críticos" fundados numa teoria social menos funcionalista do que aquela esposada pelos autores do "circulo interno" do Instituto, cujos principais representantes são Theodor W. Adorno e Max Horkheimer. ${ }^{2}$

Esses dois grupos de desbravadores parecem não ter descoberto a mesma coisa ao revisitar a obra de Franz Neumann, autor que nos interessa mais de perto. Numa primeira leitura, a abordagem de William Scheuermann, autor do mais completo e sistemático livro sobre o assunto

\footnotetext{
${ }^{1}$ SCHEUERMANN, William E. Between the Norm and the Exception. The Frankfurt School and the Rule of Law. Cambridge, MIT, 1997. Para uma reconstrução do debate constitucional durante a República de Weimar: CALDWELL, Peter C., Popular Sovereignty and the Crisis of German Constitutional Law: The Theory and Practice of Weimar Constitutionalism, Durham/London, Duke University Press, 1997. Para uma avaliação geral da revalorização de Carl Schmitt: ARATO, Andrew, "Carl Schmitt and the Revival of the Doctrine of the Constituent Power in the United States", Cardozo Law Review vol. 21, 2000, pp. 1739-1747. 2 HONNETH, Axel. "Teoria Crítica", In: GIDDENS, Anthony; TURNER, Jonathan. Teoria Social Hoje. (trad. Gilson Cesar Cardoso de Souza), São Paulo, Unesp, 1999, pp. 501-552.
} 
de que temos notícia, apesar de analisar de maneira complexa e sofisticada o trabalho de Neumann, ressaltando as múltiplas influências que sofreu em sua tentativa de combinar as perspectivas weberiana e marxista, não faz maiores considerações teóricas sobre a influência decisiva que a Teoria Crítica da Sociedade teve em seu modelo crítico. Franz Neumann, ao contrário do que Scheuermann deixa transparecer na introdução de seu livro, foi ativo participante do Instituto de Pesquisas Sociais e deixou-se influenciar pelo modo de pensar ali desenvolvido (até a década de trinta pelo menos), liderando inclusive uma posição teórica dissidente em relação ao grupo em torno de Max Horkheimer. Esses fatos parecem suficientes para mostrar que nosso autor está longe de poder ser caracterizado como um "colaborador eventual" do Instituto.

Um ponto que parece essencial para a interpretação do trabalho de Neumann é seu embate teórico com os autores ligados ao que viria a se tornar o "círculo interno" do Instituto sobre o conceito de capitalismo de Estado e sua relevância para a interpretação do nazismo, debate que dividiu o Instituto de Pesquisas no final dos anos trinta e no início dos anos quarenta. ${ }^{3}$ Esta discussão parece ter papel central na caracterização do modelo de crítica utilizado por Neumann, bem como para uma avaliação mais global de sua posição como teórico. Apesar do debate só ter ocorrido abertamente após a publicação da extensiva análise do nazismo por Neumann, Behemoth, já em The Rule of Law. Political Theory and the Legal System in Modern Society, de 1937, estão presentes os elementos que motivariam as discussões ocorridas alguns anos depois. Franz Neumann será tratado aqui como um representante da Teoria Crítica da Sociedade. Isso significa que a pergunta central que iremos formular é: qual o modelo de crítica desenvolvido por ele?

Em primeiro lugar, é estimulante perguntar: Franz Neumann é exclusivamente um teórico do direito? Os relatos historiográficos do Instituto de Pesquisas Sociais apontam que ele foi recrutado, juntamente com Otto Kirchheimer, para cumprir este papel no consorcio teórico organizado a partir do projeto de um materialismo interdisciplinar, na formulação de Max Horkheimer. Os dois deveriam integrar-se à divisão de

${ }^{3}$ NOBRE, Marcos. A Dialética Negativa de Theodor W. Adorno. A Ontologia do Estado Falso. São Paulo, FAPESP/Iluminuras, 1998, especialmente seu cap. 1; JAY, Martin. The Dialetical Imagination. A History of The Frankfurt School and The Institute of Social Research 1923-1950. Berkeley, University of California Press, 1996, pp. 143 e ss.; WIGGERHAUS, Rolf. The Frankfurt School. Its History, Theories and Political Significance. (trad. Michael Robertson), Cambridge, The MIT Press, 1998, pp. 280 e ss. 
trabalho concebida por Horkheimer, em cujo centro estava a crítica da economia política marxista e sua análise do capitalismo. O pressuposto do projeto crítico de então era a versão corrente da filosofia marxista da história em que

o desenvolvimento das forças de produção é considerado como o mecanismo central do progresso societário; juntamente com cada estágio expandido do sistema técnico do domínio sobre a natureza, esse processo também força um novo estágio nas relações sociais de produção.

Podemos inferir que, nesse contexto, o papel do teórico do Direito seria estudar o sistema jurídico e a teoria do direito sob o ponto de vista da crítica da economia política marxista, examinando qual seu papel na reprodução da dominação de classes e apontar perspectivas de emancipação por meio de uma crítica ideológica desta superestrutura.

Como mostram os historiadores do Instituto, não demorou muito a surgirem divergências agudas entre o grupo liderado por Max Horkheimer e aquele reunido em torno de Franz Neumann, centradas no conceito de capitalismo de Estado. ${ }^{4}$ Esta ruptura teórica é crucial para compreender a posição de Neumann sobre o Direito. Uma de nossas hipóteses de leitura ${ }^{5}$ é que a centralidade que o Direito adquire em suas análises do capitalismo, tanto do ponto de vista da reprodução do sistema quando do ponto de vista de uma praxis revolucionária, está estreitamente ligada a este diagnóstico divergente do capitalismo. ${ }^{6}$

\footnotetext{
${ }^{4}$ HONNETH, Axel. ob.cit., p. 509.

5 POLLOCK, Friedrich. "State Capitalism: Its Possibilities and Limitations". Studies in Philosophy and Social Sciencies, IX, 2, 1941; Idem,"Is National Socialism a New Order?", Studies in Philosophy and Social Sciencies, IX, 3, 1941. O capitalismo de Estado teria sucedido o capitalismo monopolista por ter suprimido o mercado, substituído pelo controle estatal da economia. Decorre deste fato a completa subordinação dos interesses individuais ao plano geral que rege o funcionamento da sociedade. No jargão marxista clássico, a política deixa de ser mera superestrutura para ocupar papel central na reprodução do capitalismo. Pollock afirma que seria possível pensar numa forma democrática de capitalismo de Estado, mas não avança nesta análise. Poderíamos imaginar que esta afirmação da centralidade da política devesse ser secundada pela afirmação da centralidade do Direito. Este seria o ponto ideal para iniciar uma abordagem do Direito a partir do trabalho de Pollock, trabalho este que, infelizmente para nós, não foi realizado.

${ }^{6}$ Esclarecemos que o presente texto é o primeiro resultado das pesquisas de nosso primeiro ano de Doutorado. Por esta razão, permitimo-nos apresentar diversos resultados como provisórios, deixando uma série de questões em aberto.
} 
É claro que nosso trabalho ganharia muito se tivessem sido produzidas análises do papel do Direito a partir do conceito de capitalismo de Estado. Neste caso, seria possível comparar ambas posições teóricas e sua visão do Direito, deixando claras as novas perspectivas abertas pelo diagnóstico do capitalismo defendido por Neumann. Na falta de um material como esse, quando for necessário esclarecer algum ponto relevante do trabalho do autor ou enfatizar a novidade de algum argumento, resta-nos apenas a opção de buscar termo de comparação nas teorias marxistas correntes na época, especialmente aquelas que viam no Direito mera superestrutura à serviço da dominação de classe.

$\mathrm{Na}$ abordagem marxista vulgar, o Direito não tem dignidade própria; não passa de um elemento da superestrutura ideológica à serviço da dominação do Capital. Nesse sentido, pode ser concebido como uma mera técnica à serviço do estado atual das forças produtivas, estas sim o objeto teórico por excelência da teoria marxista. De acordo com esta posição teórica, na sociedade pós-capitalista o Estado de Direito liberal deveria desaparecer, o que reafirma seu caráter marcadamente burguês, à serviço da dominação de classes.7

A abordagem de Neumann não se identifica com esse ponto de vista. Sua discordância diante do conceito de capitalismo de Estado levou-o a uma concepção diversa do Direito e de seu papel na reprodução social. Adiantando um pouco nossa argumentação, Neumann dirá que, com a efetiva participação da classe trabalhadora no Parlamento, o Direito deixa de cumprir apenas funções ideológicas. O diagnóstico do capitalismo defendido por ele considera que a política torna-se central na reprodução capitalista, neutralizando em parte o funcionamento cego das leis econômicas.

Neste ponto, seu diagnóstico concorda com Pollock e seu conceito de capitalismo de Estado. A divergência estará na afirmação de que o mundo privado ainda não foi completamente englobado pelo poder do Estado, daí ser possível falar em conflitos políticos que se expressam no Direito. A sociedade ainda não teria sido completamente englobada pela política, havendo espaço para um praxis revolucionária no interior das instituições.

Como pode-se observar, ainda que numa leitura superficial de The Rule of Law..., o Estado de Direito de origem liberal é pensado por

\footnotetext{
${ }^{7}$ Um interessante tema de pesquisa seria mapear as referências ao Direito na obra dos demais autores da Teoria Crítica na década de vinte, trabalho que escapa do objeto de nossa pesquisa, mas que poderia ser iniciado com a leitura de Dämmerung de Max Horkheimer (há tradução espanhola HORKHEIMER, Max. Ocaso. (trad. Ma. Ortega), Barcelona, Anthropos, 1986). A obra contém fragmentos escritos de 1921 a 1936, diversos deles sobre Direito e Política.
} 
Neumann como a realização parcial da utopia socialista, ou seja, trata-se de um monumental esforço para desarticular teoricamente a ligação tradicional entre Estado de Direito e capitalismo, o que permite pensar uma praxis socialista na imanência da Rule of Law, sem abdicar do objetivo de suprimir a propriedade privada dos meios de produção. Note-se que a possibilidade de pensar essa desarticulação, bem como uma eventual praxis revolucionária, está fundada na desarticulação real entre capitalismo e Direito liberal que o regime nacional-socialista realizou de fato, argumento que detalharemos adiante.

Retomando o fio da meada, a afirmação por Neumann da centralidade da política e do Direito para a reprodução do capitalismo, ponto fundamental das análises da Teoria Crítica da sociedade da época, coloca em questão as teorias marxistas que defendem sua irracionalidade essencial, tendente necessariamente ao colapso. Assim como os autores do círculo interno do Instituto de Pesquisas Sociais, Neumann também aponta para a novidade da centralidade da política, mas adota uma descrição diversa do fenômeno com consequiências divergentes, que caberá explicitar ao longo de nossa pesquisa. De qualquer maneira, a afirmação de que o Estado de Direito é a realização parcial da utopia socialista, inspirada nas obras de Karl Renner ${ }^{8}$

${ }^{8}$ Marx nunca abordou sistematicamente o problema do Direito e do Estado fazendo-o apenas em textos de circunstância ou em trabalhos de forte viés historiográfico como $O$ Dezoito Brumário, Luta de Classes na França, A Questão Judaica e A Sagrada Família. Essas afirmações referem-se muito mais ao marxismo do que a Marx propriamente dito, que ainda não foi estudado com suficiente detalhe nesses aspectos, à exceção da monumental obra de Hal Draper que trata desta questão em seu volume I: DRAPER, Hal. Karl Marx's Theory of Revolution. I: State and Burocracy. New York, Monthly Review Press, 1977, além de POULANTZAS, Nicos. O Estado, o Poder e o Socialismo. São Paulo, Graal, 2000; idem. Poder Político e Classes Sociais. São Paulo, Martins Fontes, 1977. Ressalte-se também a abordagem original de Ruy Fausto em FAUSTO, Ruy. Marx: Lógica \& Política. Tomo II. São Paulo, Brasiliense, 1987 O teórico do Direito identificado tradicionalmente com o economicismo na abordagem do Direito é PASUKANIS, E. B. A Teoria Geral do Direito e o Marxismo. (trad. Paulo Bessa), Rio de Janeiro, Renovar, 1989. Recentemente, uma nova interpretação de Pasukanis pretende inverter esta avaliação: NAVES, Marcio B. Marxismo e Direito. Um Estudo sobre Pasukanis. São Paulo, Boitempo, 2000. Sobre a questão do Estado em Marx, há o importante debate realizado na Itália reunido em BOBBIO, Norberto et alli. $O$ Marxismo e o Estado. (trad. Federica L. Boccardo e Renée Levie) Rio de Janeiro, Graal, 1979, bem como a coletânea VOGT, Winfried, FRANK, Jürgen, OFFE, Claus. Estado e Capitalismo. (trad. Ina de Mendonça e Gustavo Bayer) Rio de Janeiro, Tempo Brasileiro, 1980. Uma interessante crítica da visão do Direito por Karl Marx está em LEFORT, Claude. "Os Direitos do Homem e o Estado Providência", In: LEFORT, Claude. Pensando o Político. Ensaios sobre Democracia, Revolução e Liberdade. (trad. Eliana M. Souza), Rio de Janeiro, Paz e Terra, 1991, pp. 37-62 e LEFORT, Claude. "Direitos do Homem e Política", In: LEFORT, Claude. A Invenção Democrática. Os limites da Dominação Totalitária.(trad. Isabel Maria Loureiro), São Paulo, Brasiliense, 1987, pp. 37-69. 
e Rudolf Hilferding 9 , permite diferenciar Franz Neumann não apenas da tradição socialista de análise do Direito, mas também dos teóricos socialdemocratas de sua época e dos autores do círculo interno do Instituto. ${ }^{10}$

Neumann buscou marcar a diferença de seu pensamento em relação à teoria social-democrata. Na crítica de Lukács, esta corrente socialista atribui ao Estado funções utópicas de um lugar neutro, destinado a conciliar os conflitos entre as classes sociais. Segundo esse autor, o Estado apenas repõe a racionalidade econômica capitalista sob uma forma reificada superior ao mascarar as contradições entre as classes. ${ }^{11}$ Assim concebida, a social-democracia identifica-se com a democracia burguesa. ${ }^{12}$

Contra a social-democracia, Neumann mantém uma dimensão utópica para o socialismo - uma "meta final", na expressão de Rosa Luxemburg - ao afirmar que a realização da Rule of Law permanece incompleta sob o capitalismo. Haveria uma incompatibilidade essencial entre Rule of Law e capitalismo; incompatibilidade esta que só seria resolvida em definitivo numa sociedade sem classes. Para Neumann, a melhor descrição dessa utopia jurídica socialista (e não socialdemocrata como afirma Scheuermann) teria sido feita por Jean-Jacques

\footnotetext{
${ }^{9}$ Karl Renner também afirma que o Estado não iria desaparecer no socialismo, mas o fundamento que sustenta esta opinião não parece ser o mesmo em que Neumann se baseia. Para Neumann, as formas jurídicas burguesas são a realização parcial do socialismo. Já para Renner, essas formas jurídicas estão destinadas a permanecer: os institutos jurídicos não precisam ser mudados com o advento da ordem socialista. Neumann critica diretamente esta idéia, mostrando como será preciso modificar esses institutos liberais numa sociedade futura, mas é impossível passar ao socialismo sem sua mediação e superação. RENNER, Karl. Institutions of Private Law and Their Social Functions. London, Routledge, 2001. Veja-se também BOTTOMORE, Tom, GOODE, Patrick (orgs.). Austro-Marxism. Oxford, Clarendon Press, 1978; MARRAMAO, Giacomo. "Entre bolchevismo e social-democracia: Otto Bauer e a cultura política do austromarxismo" (trad.Carlos Nelson Coutinho, Luiz Sérgio N. Henriques e Amélia Rosa Coutinho). In: HOBSBAWM, Eric J. (org.). História do Marxismo: O Marxismo na Época da Terceira Internacional, A Revolução de Outubro, $O$ Austromarxismo. Rio de Janeiro,, Paz e Terra, 1985. Para uma breve análise da obra de Renner ver LOPES, José Reinaldo Lima. Direito e Transformação Social. Ensaio Interdisciplinar das mudanças no Direito. São Paulo, Edições Ciência Jurídica, 1997; sobre este ponto veja-se pp. 127-130.

${ }^{10}$ HILFERDING, Rudolf. O Capital Financeiro.(trad. Reinaldo Mestrinel). São Paulo, Abril Cultural, 1985.

${ }^{11}$ A respeito das discussões teóricas sobre Direito durante a República de Weimar: JACOBSON, Arthur J. \& SCHLINK, Berhard (ed.) . Weimar: a Jurisprudence of Crisis. Berkeley, University of California Press, 2000; CALDWELL, P. C. ob. cit.; HERRERA, Carlos Miguel. Les Juristes de Gauche sous la Republique de Weimar. Paris, Kimé, 2002.

12 LUKÁCS, G. ob.cit., p.217.
} 
Rousseau ${ }^{13}$. A sociedade pós-capitalista (a exemplo da sociedade capitalista) tem na Rule of Law um elemento necessário para seu funcionamento: a diferença entre a sociedade atual e a sociedade futura é que a plena realização do Estado de Direito se dará apenas com o advento do socialismo, inclusive com a supressão da propriedade privada dos meios de produção. ${ }^{14}$

Essa incorporação marxista de Rousseau dá a Neumann um critério para indicar o caminho de uma praxis emancipadora rumo ao socialismo, cuja mediação necessária é o Direito, dada a centralidade da política para a reprodução capitalista. Neumann constrói uma argumentação que, ao contrário de socialistas vulgares e fascistas, não trata o Direito como forma vazia, mera técnica à serviço do poder:

(...) the socialist society, too, will have to take recourse to the institution of the administrative act - i.e. to compulsory regulation belonging to public law. ${ }^{15}$

Nosso autor reconhece, com Marx ${ }^{16}$, que as instituições jurídicas devem sofrer alterações radicais numa ordem socialista, mas não afirma em nenhum momento que a forma Direito liberal deverá desaparecer quando da instituição da sociedade nova. Neumann busca acrescentar novas determinações à critica ao Direito feita por Marx, mostrando como as instituições burguesas podem sofrer modificações no interior de uma

13 "Mas considerando que la meta final del socialismo constituye el factor decisivo que distingue al movimiento social demócrata de la democracia burguesa y del radicalismo burgués, el factor que transforma todo el movimiento obrero de vano esfuerzo para 'apuntalar' el capitalismo en una lucha de classes contra esse sistema, para suprimirlo, el problema 'Reforma o Revolución'tal y como lo plantea Bernstein, equivale a la posición vital de la social democracia: 'ser o no ser'." LUXEMBURG, Rosa. Reforma o Revolución.(trad. Rafael Cárceres C.) Mexico-DF, Editorial Grijalbo, 1967, p. 10.

14 Cabe observar que a interpretação de Rousseau feita pelo autor tem diversos pontos problemáticos à luz da história da filosofia, especialmente no que tange à defesa que Neumann faz da permanência do conflito político mesmo com a plena realização da forma direito no socialismo, estágio em que, em termos rousseaunianos, ocorreria a plena identificação entre vontade individual e vontade geral. Trata-se de um Rousseau apropriado em suas questões fundamentais e, conforme a tradição da filosofia pós-kantiana e da Teoria Crítica da Sociedade, compreendido melhor do que ele mesmo - Jean Jacques Rousseau - poderia ter sido capaz. Por exemplo, a inspiração rousseauniana é fundamental para que nosso autor identifique o cerne material do direito formal liberal-burguês, conforme exposto adiante.

15 NEUMANN, Franz. The Rule of Law. Political Theory and the Legal System in Modern Society. Leamington, UK, 1986.

16 Idem, ob.cit, p. 44. 
mesma ordem social, na medida em que deixam de funcionar para manter e reproduzir a propriedade privada dos meios de produção. $\mathrm{O}$ socialismo não é a destruição da Rule of Law - manifestação da má negatividade mas sua conservação e superação numa forma mais plena:

This Marxian theory refers, however, only to the transition from one social order to another, in wich each social order, the old and the new, is characterized by a principal institution - for example, capitalism by private propriety [grifo nosso] in the means of production, and socialism by communal property in the means of production.

An analogous process occurs also within a given social order with regard to the principal institution characterizing it and its relations with the auxiliary intittutions and liberties. The relationship of such supplementary instituttions and liberties to the mais institution or liberty can suffer a change of function in a like manner. With a certain degree of development of the productive forces within that society, the auxiliary institutions and liberties become fettes on a hinder, the aims of the principal institution they hitherto guaranteed. ${ }^{17}$

Franz Neumann continua sua análise, mostrando como o Direito muda de função ${ }^{18}$ na passagem do capitalismo competitivo para a capitalismo monopolista, mudança esta que também provoca alterações em suas estruturas. Estas passam a conter uma menor quantidade de normas gerais, abrindo espaço para a inclusão de conteúdos morais materializados nos textos jurídicos positivos. A materialização do Direito, descrita com inspiração na análise weberiana da racionalização do Direito19, permite maior grau de discricionaridedade por parte dos órgãos encarregados de aplicar as normas jurídicas. ${ }^{20}$ Esse será o espaço institucional privilegiado para pensar a revolução na imanência da forma direito, pois abre-se a possibilidade de submeter o mercado, portanto a propriedade privada, aos

${ }^{17}$ Idem, ob. loc. cit.

18 Idem, ob. loc. cit.

19 Esta idéia da mudança de função do Direito é claramente inspirada em RENNER, Karl. ob.cit.

${ }^{20}$ WEBER. Max. Economia y Sociedade. (trad. José Medina Echevarría et alli.). Mexico-DF, Fondo de Cultura Economica, 1999. 
desígnios políticos da coletividade, via Direito. ${ }^{21}$

Conforme o esboço de análise acima, a posição teórica de Neumann é claramente diversa da social-democracia. Quanto às divergências em relação aos autores do círculo interno do Instituto, caberá a este trabalho de pesquisa demonstrar que Franz Neumann adota um modelo de crítica que reserva ao Direito e à Política o centro do espectro teórico, em razão do diagnóstico do estado do capitalismo adotado por ele, fundado na obra $O$ Capital Financeiro de Rudolf Hilferding. ${ }^{22}$ A partir deste pressuposto, sua análise da politização do capitalismo por meio do Direito permite-lhe afirmar, com base em Rousseau e Weber relidos via Marx, que $o$ Estado de Direito já significa a realização parcial do socialismo, ou seja, que a Rule of Law burguesa tem um conteúdo ético ${ }^{23}$ que transcende a sociedade dividida em classes, conteúdo ético este que será completamente desenvolvido quando da plena realização do Estado de Direito na sociedade futura, com a supressão da propriedade privada dos meios de produção.

$* \quad * \quad *$

Esta apresentação aparentemente desorganizada dos inúmeros fios teóricos e questões que Franz Neumann tenta cozer simultaneamente em The Rule of Law... liga-se à nossa hipótese global de leitura da obra. A vertiginosa sucessão de problemas e possíveis soluções teóricas apresentadas nos parágrafos precedentes, testemunham a imensa quantidade de pontos obscuros que Franz Neumann conseguiu, nessa obra, identificar no pensamento sobre o Direito e sobre seu tempo. O objetivo do autor parece

21 Franz Neumann busca demonstrar que o avanço do processo de "desencantamento do Direito" implica no desaparecimento do Direito Natural, encarnado em instituições como o Parlamento e o direito adquirido. Estas instituições constituem um entrave real ao poder do Estado, desde que funcionem como veículo dos conflitos sociais. Com este aparato teórico é possível pensar o Direito para além do Direito positivo, sem a necessidade de apelar para uma instância transcendente ao mesmo, capaz de fornecer critérios para julgar sua correção. Neumann troca a oposição Direito natural versus Direito positivo pela contraposição entre “'political Rule of Law" e "'material Rule of Law", numa das tentativas mais originais e provocadoras de pensar um critério que sirva para julgar a correção do Direito positivo a partir de sua imanência mesma, evitando assim que ele seja reduzido a uma forma vazia.

22 Neumann desdobra sua elaboração teórica em uma crítica cerrada e minuciosa das instituições liberais, defendendo, v.g, uma nova concepção de separação dos poderes, centrada nas funções executiva e legislativa. Esta visão leva-o a redimencionar o papel do poder judiciário - visto também como criador de normas jurídicas e não apenas aplicador de normas prontas, elaboradas pelo Parlamento - e portando resulta numa nova visão do Estado. Não há espaço aqui para entrar nos detalhes dessa complexa análise.

${ }^{23}$ HILFERDING, Rudolf. ob.cit.. 
ter sido a de confrontar as teorias de sua época - tanto de extração burguesa quanto de inspiração marxista - com o enigma do regime nacionalsocialista, que colocou todos os seus respectivos pressupostos em questão.

A Alemanha nazista e sua forma de não-Direito (de não-Estado, conforme dirá em Behemoth) é vista por Neumann como uma imensa incógnita que parece resistir, com sua opacidade essencial, a qualquer das teorias à disposição dos analistas que buscassem decifrá-la. Numa primeira leitura de The Rule of Law ..., parece que estamos diante de uma análise inspirada no modelo lukasiano da crítica às antinomias do pensamento burguês, ou seja, trata-se de colocar a teoria diante daquilo que ela não consegue explicar com o objetivo de explodir por dentro seu aparelho conceitual.

Lukács afirma que, a partir do inexplicado, do irracional, revelado pelo fracasso de uma determinada abordagem teórica - que cabe ao teórico crítico identificar - pode-se encontrar os pontos de estrangulamento dos conceitos, processo que permitirá ascender na direção do conhecimento da totalidade. O papel da crítica é colocar em xeque os pressupostos que fundamentam o aparelho conceitual, mostrando que o inexplicado passará ser compreendido quando deixar de ser olhado a partir de um ponto de vista parcial. É preciso recolocá-lo na totalidade que lhe dá sentido, abandonando a parcialidade que a crítica desvelou. ${ }^{24}$

Daí a importância central que a crise assume numa análise crítica pensada nesses termos. Ao revelar algo que escapa ao aparelho conceitual das ciências - uma irracionalidade que irrompe sem aviso e revela a contingência de leis científicas tidas como coerentes - a crise torna acessível a irracionalidade do todo à luz do aparelho conceitual fracassado, evidenciando algo que escapa à racionalização, rompendo com o todo supostamente fechado, falsamente figurado pela teoria. ${ }^{25}$

24 NEUMANN, Franz. The Rule of Law..., p. 256.

25 LUKÁCS, G. História e Consciência de Classe. Porto, Publicações Escorpião, 1974, p. 122. Lembremos que essa tarefa teórica não é exclusivamente teórica e tem alcance limitado do ponto de vista dapraxis revolucionária. Lukács afirma que, sem colocar em xeque os pressupostos da teoria burguesa é impossível ascender à totalidade. Mas ressalte-se que uma modificação radi cal de ponto de vista é impossível no campo da sociedade burguesa. Para que a filosofia rompa com essas barreiras metodológicas seria necessário pôr em evidência os fundamentos, a gênese e a necessidade desta maneira de fazer teoria. Seria necessário que as ciências particulares especializadas não estivessem ligadas mecanicamente numa unidade, mas readaptadas, também interiormente, pelo método filosófico internamente unificante. Para Lukács, a filosofia da sociedade burguesa é incapaz disso. Ademais, a reforma completa do ponto de vista é uma processo que não se resolve apenas teoricamente, mas que também demanda uma praxis que solape os fundamentos materiais da especialização da ciência burguesa. $\mathrm{O}$ acesso ao ponto de vista da totalidade é simultâneo à marcha da revolução. Nesse sentido, Lukács pressupõe aqui que a praxis revolucionária já está em curso e, portanto, não há separação entre teoria e praxis. 
O momento de ruptura de Franz Neumann com Carl Schmitt durante a República de Weimar ${ }^{26}$ é central para explicar sua valorização do Direito e do conflito na reprodução da sociedade, bem como para pensar sua visão do nacional-socialismo. A crise política e institucional instaurada na República de Weimar alimenta a crise teórica de Franz Neumann, que marca seu rompimento com Schmitt, bem como permite-lhe acesso intelectual à crise do aparelho conceitual da ciência burguesa sobre o Direito e a sociedade.

Essas três crises aparecem entrelaçadas na construção de The Rule of Law... que pode ser visto como signo de uma ruptura radical, momento do trabalho do negativo que dissolve, em todos os níveis, as certezas pessoais e teóricas de nosso autor. Nada mais próximo de uma figura do desespero da razão, colocada face a face com um monstro (batizado alguns anos depois com o nome próprio de Behemoth por nosso autor), do que essa obra dilacerada, construída com estilhaços de teorias mais ou menos caducas, que Neumann toma como sua tarefa tentar articular.

Franz Neumann dirá em The Rule of Law... que o nazismo é a realização efetiva do decisionismo schmittiano. Nesta construção revelase, numa só expressão, as dimensões objetiva e subjetiva das três crises apontadas acima: o monstro do decisionismo schmittiano torna-se carne na Alemanha, efetivando o que poderia parecer impossível à luz da teoria. Trata-se então de examinar o monstro; explicar como ele foi possível, juntando os cacos teóricos que ainda mantêm algum poder de figuração.

A imensa quantidade de teorias e teóricos que aparecem nas páginas de The Rule of Law... não é sinal de dispersão, tampouco é mera casualidade - podemos citar Karl Marx, Karl Renner, Rudolf Hilferding, Jean-Jacques Rousseau, Immanuel Kant, Georg Friedrich Hegel, Max Weber e Carl Schmitt, só para ficarmos com os principais. Essa aparente dispersão é resultado do desespero da razão face a face com o inexplicado; trabalho de alguém que se dedicou a olhar fixamente os olhos da besta para buscar trazer dessa experiência possibilidades teóricas renovadas.

Do ponto de vista do marxismo, o impossível nazista revela-se particularmente inquietante. Franz Neumann coloca-nos diante de uma descrição desse regime a partir de suas instituições jurídicas. O ponto de vista privilegiado da descrição é o Direito sob o capitalismo que, segundo a formulação weberiana clássica, deveria exercer o papel de garantir a pre-

26 É interessante notar que no texto "Reificação e consciência do proletariado", parte de História e Consciência de Classe, Lukács identifica esse modelo de crítica em Marx - na sua Crítica à Economia Política - passando em seguida a aplicá-lo ao Direito e à Filosofia do Idealismo alemão. 
visibilidade necessária para o bom funcionamento do mercado. ${ }^{27}$ Olhado desse ponto de vista, o Direito precisa tornar-se cada vez mais formal, afastando de si quaisquer conteúdos morais e subjetivos pela adoção de normas gerais e abstratas, que se colocam à serviço do aprofundamento da racionalidade conforme a fins, tipicamente capitalista. ${ }^{28}$

Nada mais distante do regime nacional-socialista do que esta formulação de um direito capitalista racional-formal. É nesse sentido que Neumann irá afirmar estar diante da supressão do Direito de caráter não socialista. ${ }^{29} \mathrm{O}$ processo de ascensão do nazismo buscou varrer da face da Alemanha a legalidade liberal, igualmente desprezada pela tradição socialista como o supra-sumo da alienação. ${ }^{30}$ Mais do que isso, do ponto de vista do marxismo, apenas na sociedade socialista futura é que o Direito liberal-burguês seria suprimido. Ao afirmar que o Direito foi atualmente suprimido pelo nazismo, Neumann contribui para desarticular essa versão da crítica marxista ao Estado de Direito. O funcionamento real de um sistema capitalista sem a presença do Direito liberal é motivo mais do que suficiente para levantar um mar de dúvidas sobre o diagnóstico marxista do Direito como mera superestrutura.

Diante de um curto-circuito tão claro, em que a tradição conservadora e autoritária alemã e um certo socialismo colocavam-se como igualmente críticos à democracia liberal-burguesa, qualquer crítica ao Estado de Direito favorecia o regime fascista, alimentando sua tendência à destruição do Direito. A identificação desta tendência e suas possíveis conseqüências

27 Toda a formação de Franz Neumann deu-se durante a República de Weimar. Grande parte do debate teórico realizado nessa época é incorporado por ele em seus trabalhos. Uma boa reconstituição deste debate pode ser encontrada em CALDWELL, P. C., ob. cit.

28 WEBER. M. ob. cit.

29 Olhado do ponto de vista típico-ideal, o problemático conceito de racionalidade weberiano não pode ter um conteúdo ontológico necessário. Assim, do ponto de vista de uma racionalidade conforme a valores, a formalização do direito seria considerada irracional. Segundo este ponto de vista, racionalização significaria aumento da materialização do direito, ou seja, a inclusão da dimensão moral e subjetiva no ordenamento jurídico que resultaria, no limite, na supressão das normas gerais e abstratas em favor do juízo subjetivo e arbitrário de um indivíduo.

${ }^{30}$ As análises de Neumann sobre o funcionamento do Direito no regime nazista devem muito ao livro FRAENKEL, Ernst, Il doppio Stato: Contributo alle teoria della dittadura. (trad. Pier Paolo Portinaro). Torino, Einaudi, 1983, mas têm uma feição muito mais radical por incluir a idéia da supressão do direito liberal pelo nazismo. Neumann não adota a explicação dualista do nazismo que o livro defende, em que direito e ausência de direito estariam presentes simultaneamente no mesmo Estado. Fraenkel afirma que, sob o nazismo, conviviam lado a lado dois tipos de Estado, cada um deles atuando com uma racionalidade própria: o chamado "Estado normativo" mantinha a racionalidade do direito liberal funcionando de forma seletiva e excludente, ao lado do "Estado discricionário", marcado pelo arbítrio e pela violência. O autor não demonstra os pontos de articulação entre os dois pólos dessa dualidade, limitando-se a colocar esses dois Estados lado a lado, sem explorar convincentemente suas mediações. 
forçou Neumann a realinhar seus conceitos sem abandonar a tradição socialista, mas dando-lhe uma versão original.

O principal problema de Neumann é a evidência da instauração de um poder sem medidas, de um poder absoluto sem o controle da forma direito (Rule of Law) - marcado pela redução da forma jurídica a uma mera forma, mero invólucro para decisões completamente arbitrárias ${ }^{31}$ convivendo lado a lado com um regime capitalista. Essa situação é apresentada como a realização prática do decisionismo schmittiano, que nada mais é do que a supressão do Direito, reduzido a uma mera técnica, forma vazia a serviço da força bruta, sem qualquer dignidade própria, pois despido do conteúdo ético que lhe é essencial. ${ }^{32}$ The Rule of Law... termina com a seguinte afirmação:

We therefore sum up: That law does not exist in Germany, because law is now exclusively a technique of transforming the political will of the Leader into constitucional reality. Law is nothing but an arcanum dominationis.

Esquematizando um pouco os argumentos do autor temos, de um lado, a realização completa do Direito na sociedade futura, que consiste na permanência de uma certa tensão entre vontade individual e vontade geral

${ }^{31}$ Esta coincidência involuntária de perspectivas sugere uma reflexão sobre o significado da retomada de diversos conceitos de Carl Schmitt por alguns teóricos contemporâneos não identificados abertamente com uma posição conservadora, muito pelo contrário. $\mathrm{O}$ exemplo central é AGAMBEN, Giorgio. Homo Sacer - O Poder Soberano e a Vida Nua. Belo Horizonte, Ed. UFMG, 2002 e idem. Lo stato di eccezione. Bollati Boringhieri, 2003.

${ }^{32}$ Em MÜLLER, Ingo. Hitler's Justice: The Courts of the Third Reich. (trad. Deborah Lucas Schneider), Cambridge (Mass.), Harvard University Press, 1991, há uma análise impressionante da formação e do funcionamento do Poder Judiciário alemão, composto por membros da elite conservadora prussiana, fiel ao ideário do Império. Os juízes alemães posicionaramse de modo claramente tendencioso em relação aos atentados nazistas durante a República de Weimar, antecipando a desmedida, a irracionalidade jurídica, que caracterizará o regime nacional-socialista. Isto fica muito claro com a comparação que Ingo Müller faz entre esses julgamentos e aqueles que envolviam militantes socialistas. É quase inacreditável ler as transcrições de partes das sentenças e das audiências. As sentenças, que quase sempre absolviam os criminosos nazistas ou aplicavam-lhes penas irrisórias, eram repletas de elogios explícitos e entusiasmados à sua "ação patriótica". Na audiência do processo sobre o incêndio do Reichstag, Göring, um dos ouvidos em juízo, aos gritos, fez ameaças explícitas ao advogado de defesa e aos acusados, sob a complacência do magistrado que presidia os trabalhos. Muito mais grave do que tudo isso é perceber que, mesmo antes de Hitler assumir o poder total na Alemanha, as Cortes já trabalhavam com um standard jurídico que seria fundamental para a prática de atos arbitrários sob o regime nazista: "o bem do povo alemão". Essa constatação aparentemente reforça a análise de Neumann da materialização do Direito sob o capitalismo monopolista. 
(definidas em termos rousseaunianos) ${ }^{33}$ figuradas por normas gerais abstratas que tornariam as decisões dos aplicadores do Direito racionalmente previsíveis. ${ }^{34}$ Este o estágio final do processo de racionalização do Direito. ${ }^{35}$

De outro lado, no ponto mais baixo e degenerado do espectro teórico, temos o decisionismo schmittiano, realizado efetivamente na sociedade nazista. Em termos weberianos, sempre tomando como referência a necessidade capitalista de um agir conforme a fins - a necessidade de um direito racional-formal, composto de regras gerais e abstratas - o nazismo seria um processo de regressão da racionalização do direito, marcado pela materialização a níveis extremados, tendente à supressão do Direito..

Dizer que a Alemanha vivia a supressão do direito significava para Neumann que o conflito político também havia sido suprimido da

33 É interessante notar que a Constituição alemã atual, redigida após a Segunda Grande Guerra e promulgada em 23 de maio de 1949, garante a supremacia da Constituição mesmo contra a soberania popular e permite a formulação dos pares antinômicos: "Estado de Direito" e "Estado de não-direito", bem como "Democracia com Estado de Direito" e "Democracia sem Estado de Direito". Verbis: "Article 20 [Basic institucional principles; defense of the constitucional order]. (1) The Republic of Germany is a democratic and social federal state. (2) All state authority is derived from the people. It should be exercised by the people through elections and other votes and through specific legislative, executive and judicial bodies. (3) The legislature shall be bound by the constitucional order, the executive and the judiciary by law and justice.(4) All germans shall have the right to resist any person seeking to abolish this constitucional order, if no other remedy is available." (tradução para o inglês publicada no site do Parlamento alemão - www.bundestag.de). O art. 20, (3), da Constituição alemã, diz claramente que a soberania popular está submetida à ordem constitucional, o que significa que ela não existe fora do Estado de Direito. Conforme a interpretação de HESSE, Herman. Elementos de Direito Constitucional da República Federal da Alemanha. (trad. Luís Afonso Heck). Porto Alegre, Sergio Antonio Fabris, 1998, pp. 113-114, o elemento fundamental da ordem estatal é o princípio democrático, garantido pelo art.20, (1), da Constituição alemã, unido ao Estado de Direito na forma de um "estado social de direito". O autor explica que essa construção dogmática é uma "reação contra o desprezo pelos princípios estatal-jurídicos na época do regime nacional-socialista".

${ }^{34}$ Note-se que Neumann não defende a identificação de vontade geral e vontade individual na sociedade futura e portanto, parece que estamos diante de um autor marxista que efetivamente abandona o modelo do Absoluto hegeliano como meta final da Revolução socialista. Se levarmos em conta a conhecida afirmação de Adorno de que Marx apenas invertera o modelo hegeliano, colocando o Absoluto no final do processo ao invés do começo, nossa constatação ganha uma relevância ainda maior. Mas este argumento demanda maior análise do texto de Neumann para ser adequadamente justificado.

35 É preciso tomar cuidado nesta questão, pois Neumann é o primeiro a afirmar que a materialização do direito é inevitável na fase monopolista do capitalismo: não estamos diante de um detrator do direito materializado. Não sabemos ainda qual o significado exato da previsibilidade jurídica advogada por Neumann, mas certamente não será aquela defendida por teóricos iluministas como Sieyès, para quem os Códigos poderiam ser tão perfeitos, se conformes aos princípios da razão, que qualquer indivíduo seria capaz de aplicá-los aos casos concretos que se lhe apresentassem. Nesta perspectiva teórica - cuja fonte primeva é $O$ Espírito das Leis 
sociedade. O regime fascista promoveu, ao mesmo tempo, a materializa ção do direito e a eliminação do conflito político, subtraindo o conteúdo ético que caracterizaria o Direito como tal, o que o teria transformado em mera técnica. São acrescentadas aos textos jurídicos expressões indeterminadas como "a vontade do Führer", capazes de tornar completamente arbitrárias as decisões do aplicador da norma, abrindo espaço para a eliminação sistemática do antagonismo político e, portanto, transformando a forma direito em forma vazia.

O que é mais espantoso nesse processo - tanto do ponto de um certo socialismo quanto da análise weberiana do capitalismo - é sua convivência pacífica com o sistema capitalista. O sistema continua a funcionar, imerso em um estado de normalidade, mesmo diante da irracionalidade material do direito que lhe serve de sustentação institucional. ${ }^{36}$ Podemos levantar a hipótese de que, se é possível pensar numa racionalidade material do direito posta a serviço da racionalidade conforme a fins capitalista, parece plausível levantar dúvidas sobre o poder do aparelho conceitual weberiano de captar o sentido que os agentes sociais conferem à sua ação: ao invés de mais formalização o capitalismo monopolista demanda maior materialização, processo levado à degenerescência pelo nacional-socialismo.

de Montesquieu - o procedimento judicial ficaria reduzido a um juízo de fato, ou seja, à verificação dos fatos previstos na lei diante do caso concreto. Como diz Montesquieu "Les juges de la nation... ne sont que la bouche qui prononce les paroles de la loi, des êtres inanimés, qui n'en peuvent modérer ni la force ni la rigueur." A figura do técnico em direito seria característica de uma ordem jurídica marcada pela multiplicidade e irracionalidade das leis. (Sobre este ponto BOBBIO, Norberto. O Positivismo Jurídico. Lições de Filosofia do Direito . (trad. Márcio Pugliesi, Edson Bini e Carlos E. Rodrigues, São Paulo, Ícone, 1995, p. 67 e NEUMANN, Franz. The Rule of Law..., pp.224 e ss.) Se o conceito de previsibilidade de Neumann não é este, é preciso imaginar qual seria seu conceito de certeza e segurança jurídica. William Scheuerman, neste ponto, faz uma interpretação um pouco apressada da posição de Neumann, entendida como uma defesa do Direito contra a materialização, tomada em seu sentido weberiano. Parece que Neumann caminha no sentido de uma idéia de materialização racional do Direito em que materialização não significa necessariamente irracionalidade.

36 Como dito acima, Neumann toma Weber como descrição do real e não como um autor que analisa a sociedade por intermédio de tipos ideais. Nesse sentido, faz uma reconstrução do pensamento weberiano sobre o Direito dando-lhe um sentido evidentemente diferente do original. Neumann ressalta o fato de que a previsibilidade, que é a razão básica para o desenvolvimento histórico da Rule of Law, na verdade passa a atrapalhar o pleno funcionamento da economia no momento em que as demandas sociais passam a ser incorporadas ao direito positivo, criando-se assim uma incompatibilidade entre as duas esferas. Isso fica claro com o nazismo, que implementa o capitalismo por intermédio do esvaziamento do conteúdo ético da forma direito, reduzida a mero invólucro de decisões arbitrárias; acompanhada da supressão do conflito político, ou seja, a neutralização do poder subversivo da classe operária. 
Diante desse quadro, com o auxílio dos conceitos à sua disposição, Franz Neumann recusa-se a identificar, sob o regime capitalista, materialização e irracionalismo ${ }^{37}$, identificação esta aceita por muitos teóricos, até os dias atuais. ${ }^{38}$ Para Neumann, seria possível falar numa racionalidade e num processo de racionalização do direito mesmo diante do desenvolvimento do capitalismo monopolista (que traz consigo, é bom reforçar, necessariamente, a materialização do direito). Aqui a justificativa de sua defesa do Estado de Direito contra o nazismo - e contra parte das teorias socialistas - e seu esforço por subtrair a cópula da expressão "Estado de Direito liberal e burguês".

Nossa hipótese de leitura neste ponto é que Neumann pode estar indicando um caminho para a superação do quadro conceitual weberiano

37 Tanto Neumann quanto Schmitt utilizam o conceito de instituição em suas análises do Direito, inspiradas pelas teorias institucionalistas francesas. Sobre a leitura do institucionalismo por Carl Schmitt, v. MACEDO Jr., Ronaldo Porto. Carl Schmitt e a Fundamentação do Direito. São Paulo, Max Limonad, 2001. O autor mostra como Schmitt incorpora o institucionalismo como crítica ao direito liberal, pensando o funcionamento do Estado em épocas de normalidade política. Seria muito interessante comparar essas duas incorporações do institucionalismo, porquanto parece ser possível demonstrar que certa normalidade institucional é comum tanto a regimes totalitários quanto a regimes democráticos: a diferença está no fundamento dessa normalidade política. Nesse sentido, o institucionalismo lido por Schmitt ganha um registro irremediavelmente fascista, inescapavelmente conservador e radicalmente antidemocrático. Em sua teoria há sim espaço para a construção de uma certa normalidade, mas desde que fundada no arbítrio, sob o signo do par conceitual amigo-inimigo e da soberania entendida como a possibilidade de decidir fora do direito e a qualquer momento, sobre quem deve ser considerado inimigo (e, portanto, quem deve ser fisicamente eliminado da sociedade). Em Schmitt, o institucionalismo é secundário e instrumental, forma vazia a serviço da soberania. Em nossa opinião, se existe algo central no pensamento de Carl Schmitt é seu peculiar conceito de soberania e a defesa da formação de uma comunidade, responsáveis por uma concepção de normalidade política essencialmente instável e temporária, subtraída de qualquer antagonismo político relevante, visando à homogeneidade cultural e ideológica contra o pluralismo político, na esteira do que havia de mais retrógrado e autoritário na tradição do pensamento conservador alemão. Sobre este ponto v. BREUER, Stefan. La Rivoluzione Conservatrice: Il pensiero di destra nella Germania di Weimar. (trad. Camilla Miglio). Roma, Donizelli Editore, 1995; BEAUD, Olivier. Les Derniers juors de Weimar: Carl Schimitt face à l'avènement du nazisme. Paris, Descartes \& Cie, 1997; MOSSE, George L. The Crisis of German Ideology: Intellectual Origins of the Third Reich. Nova Iorque, Howard Fertig, 1998; MALDONADO, Tomás (org.). Tecnica e Cultura: Il debattito tedesco fra Bismark e Weimar. Milano, Feltrinelli, 1991; BOLAFI, Angelo. Il Crepuscolo della Sovranità. Filosofia e polit ica nella Germania del Novecento. Roma Donizelli Editori, 2002. A formação real de um pólo de poder total na Alemanha nazista é ressaltada por Franz Neumann em The Rule of Law..., bem como nas obras: ARENDT, Hanna. Origens do Totalitarismo. (trad. Roberto Raposo). São Paulo, Cia das Letras (especialmente em seu capítulo final); KERSHAW, Ian. Hitler: 1889-1936. Hubris. London, Penguin, 1998; HILBERG, Raul. The Destruction of European Jews. Harpercollins College Div, 1979; além do citado livro de Ingo Müller.

38 NEUMANN, Franz. The Rule of Law ..., pp. 29-31 
na ligação necessária que estabelece entre a permanência da forma Direito e a presença do conflito político, bem como de sua expressão em cláusulas gerais, no Parlamento, no direito adquirido e em outros institutos jurídicos. A ausência de conflito político e de sua institucionalização seria o diferencial entre um regime fascista e outro democrático, ambos marcados pela materialização do direito. Num caso, teríamos a presença da forma direito como mediação dos conflitos políticos e, no outro extremo, a materialização irracional do decisionismo schmittiano, ou seja, a supressão nazista da forma direito.

Por esta razão, será possível para o autor afirmar que o direito liberal tem um cerne material que lhe é essencial ${ }^{39} \mathrm{E}$ é esta a característica que abre a possibilidade de pensar a transcendência da forma direito liberal em relação ao regime capitalista pois, sob o capitalismo monopolista, $o$ direito liberal deixa de ser mera forma ao garantir um entrave ao poder despótico na forma da Rule of Law. Além disso, ao normalizar o mercado, incluindo o conflito distributivo dentro do Direito - pois a classe operária passa a tomar parte no processo parlamentar, incorporando suas reivindicações na forma de lei - abre-se a possibilidade de agudizar esse processo de relativização da propriedade privada, cujo estágio final seria a supressão da propriedade privada dos meios de produção.

Retrocedendo um pouco na argumentação, Neumann afirma, com Hilferding, que, no capitalismo em fase monopolista, a intervenção do Estado elimina a seleção natural do mercado por meio de tarifas, impedimento de importações, proibição da criação de novos empreendimentos e pela criação compulsória de cartéis. ${ }^{40} \mathrm{O}$ resultado é o fim do livre empreendedor, transformado num funcionário do empreendimento e colocado a serviço dos acionistas. Como conseqüência, o conflito transfere-se da arena da luta de classes para a esfera do Estado, ou seja, para o âmbito

39 SCHLUCHTER, Wolfgang. The Rise of Western Rationalism. Max Weber Developmental History.(trad. Guenther Roth). Berkeley, California University Press, 1985.

40 Caso nossa leitura esteja correta, parece ser plausível a hipótese de uma ruptura com o aparelho conceitual weberiano ao encontrarmos em Neumann uma defesa da convivência do direito material e do direito formal, ponto que se contrapõe ao sentido da racionalização weberiana “... embora a ação seja racionalizável no interior de cada uma dessas esferas (a da racionalidade formal, voltada para a maximização de um fim qualquer, e a da racionalidade substantiva, amarrada a uma determinada consideração valorativa), não é possível obter-se uma racionalidade abrangente, que envolva, ao mesmo tempo, as ações no interior de cada esfera e as ações entre componentes de ambas." COHN, Gabriel. "Sobre o significado da racionalização". In: Crítica e Resignação: Max Weber e a Teoria Social. São Paulo, Martins Fontes, 2003, pp. 241-242. 
político. Isso fica claro na Alemanha de Weimar, cuja formação institucional fundou-se em uma série de contratos sociais em que o Estado atuou como terceiro neutro em relação aos interesses das classes. ${ }^{41}$

O Direito sofre diversas modificações nesse processo, mas a questão central é a incorporação de standards legais no ordenamento jurídico, que modificam inclusive a estrutura de parte das normas jurídicas e, conseqüentemente, sua forma de aplicação: ao invés de normas que prevejam hipóteses gerais e abstratas de conduta, pressupondo a ocorrência de certos fatos na realidade, temos agora regras que incorporam expressões de significado deliberadamente impreciso e vago para que o aplicador da norma possa ter um grau mais amplo de discricionaridade em sua aplicação. Por exemplo, a idéia de "boa fé" no direito privado. ${ }^{42}$

Neumann trata esses standards legais de forma bastante sofisticada, mostrando como revelam as contradições entre o Direito liberal e o capitalismo. De um lado, eles são inevitáveis e até mesmo necessários: é preciso adotar essa forma de regulação para que o Estado possa realizar suas funções de mediação do conflito entre as classes. É também pelos standards que o conflito se expressa institucionalmente:

Legal standars fulfil theis decisive function in any law which deals with the relations of monopolies. They appear wherever the legal system is confronted with the problem of private power. ${ }^{43}$

De outra parte, esses mesmos standards podem colocar em perigo a racionalidade do Direito, caso sejam disseminados indiscriminadamente pelo ordenamento jurídico e caso o conflito político deixe de preenchê-los com seu conteúdo, necessário para o funcionamento da Rule of Law. Forçando um pouco a explicação, o decisionismo de Carl Schmitt poderia ser descrito como a defesa de um sistema jurídico dotado de uma única norma suprema com a forma do standard legal : "a lei é a vontade do Führer".

Nesse sentido, considerada a realidade da eliminação do conflito político e a plena centralização do poder, nas mãos do Führer e de um pequeno grupo de pessoas, poderíamos levantar a hipótese de que o regime

\footnotetext{
41 NEUMANN, Fraz, ob. cit. pp. 266 e ss.

42 Idem, ob.cit., p. 271.

43 Esta discussão é central para o Direito brasileiro atual, especialmente após a promulgação do Novo Código Civil, e está longe de estar resolvida. O estudo da obra de Neumann pode trazer novos elementos para esse debate. Para o estado atual da questão vide MARTINSCOSTA, Judith H. A Boa-Fé no Direito Privado. São Paulo, Revista dos Tribunais, 1999.
} 
nacional-socialista realizou de forma completa a certeza e segurança jurídicas, demandas características do direito liberal-burguês. Ao invés da plena imprevisibilidade, como afirma a maior parte dos teóricos do regime nazista, temos a previsibilidade completa de um sistema em que não há surpresas nascidas da sociedade.

Nesse regime, os responsáveis por tomar as decisões relevantes formam um pequeno grupo de pessoas que age conforme uma rígida ideologia e realiza barganhas entre $\mathrm{si}^{44}$, estas, muito menos perturbadoras para o bom funcionamento do mercado do que o conflito distributivo aberto, protagonizado pela classe operária. Nada mais adequado para o funcionamento capitalista do que esse ambiente de total ausência de oposição operária - ou de oposição tout court - e portanto, da quase que completa previsibilidade das decisões das autoridades públicas. A supressão nazista do Direito cria um ambiente ideal para o funcionamento do capitalismo, a despeito (ou quem sabe pour cause) de sua desumanidade.

Para Neumann, a persistência da forma Direito está ligada ao fato de que o preenchimento do sentido dos standards deve ser realizado num contexto de conflito político. Na realidade, a forma Direito só faz sentido do ponto de vista da emancipação da sociedade, ou seja, do ponto de vista socialista, se operar num contexto marcado pelo conflito mediado pelo Estado. Prova disso é a seguinte afirmação: o Direito só exerce a função de ocultar o poder da burguesia quando a classe operária não tem uma participação efetiva no parlamento.

We have, therefore, not two functions standing in an antagonistic relationship: law is, so to speak, an expressive ideology [Ausdrucksideologie] but it is at the same time, a veilling [Verhüllungsideologie]. The latter funcion has two aspects. It veils the rule of the burgeoisie, since the invocation of the rule of law makes it unnecessary to name the real rulers in society; at the same time, the invocation of the rule of law veils the unwillingness of the rulling classes for social reform. (...) This, however, implies that the emphasis laid upon the rule of law depends upon the fact that Parliament on the whole is a representation of burgeois interests, that is to say, that the proletariat has not reached the stage of being a political power dangerous to the interests of burgeoisie. ${ }^{45}$

${ }^{44}$ NEUMANN, Franz, ob. cit., p. 279.

45 Este ponto será extensamente analisado por Neumann no seu livro posterior, Behemoth. 
Anovidade do regime nazista despertou a necessidade da reconstrução teórica neumanniana, constatado o fundamento irracional do regime capitalista em fase monopolista, agudizado pelo fascismo alemão. Tomando como contraponto a análise lukacsiana, a forma direito teria cessado de exercer a função de ocultar a irracionalidade da parte sob a aparência de racionalidade do todo. Na descrição de Lukács (aqui fortemente influenciada por Max Weber), sob o regime capitalista o Direito precisa ser racional, ou seja, baseado em regras gerais que são aplicadas mecanicamente pelo juízes. Como o processo de produção de mercadorias pela empresa, o Direito também sofre uma sistematização racional no sentido da formação de um sistema fechado, capaz de prever todos os casos de conflitos futuros. Só assim o Direito poderia colocar-se a serviço do cálculo exato de possibilidades futuras, necessário para dar uma aparência racional à irracionalidade do capitalismo.

Numa síntese quase indecente do pensamento de Lukács, poderíamos dizer que o sistema jurídico opõe-se aos acontecimentos particulares da vida social com potencial anti-sistêmico, negando sua peculiaridade, ou seja, apresentando-os como subsumíveis a leis gerais e abstratas que aparentemente os normalizam. Dessa maneira, o Direito mantém-se como sistema aparentemente racional, a despeito do fato de que o capitalismo não cessa de revolucionar a si mesmo. Do ponto de vista do sujeito, o sistema jurídico dá a aparência de continuidade e estabilidade para um sistema em constante convulsão. Assim, o Direito contribui para reproduzir a atitude contemplativa do sujeito que busca apenas calcular e prever as hipóteses possíveis de evolução do sistema, evitando a arbítrio individual e tentando não intervir em seu bom funcionamento.

Ora, num Estado em que o Direito torna-se irracional não seria mais defensável a idéia de que sua função essencial seria a de ocultar a irracionalidade que se insinua nas franjas do sistema. A irracionalidade passa a ser a norma: a desmedida está a serviço da reprodução normal do sis tema capitalista. $\mathrm{O}$ que é mais surpreendente na análise de Neumann é que essa irracionalidade do direito material surge como algo de necessário na fase monopolista do capitalismo, aprofundando-se de forma nefasta sob o regime nazista. A irracionalidade material do Direito não é uma monstruosidade, é algo que decorre do desenvolvimento normal do capitalismo. Monstruosa é sua degradação nazista em forma vazia, mera técnica a serviço da força. 
Daí a tentativa de Neumann de pensar a materialização num sentido racional e socialista ao afirmar a transcendência ética do Direito liberal. Forçando um pouco a argumentação, poderíamos dizer que um sistema jurídico que contivesse apenas um standard seria ainda um sistema jurídico (não seria a supressão do Direito), desde que o conflito político fosse mantido como elemento atuante no preenchimento de seu sentido. Nesse caso, parece que restaria algo do sentido ético transcendente que Neumann atribui à Rule of Law.

No caso do nazismo, afirmar que "a lei é a vontade do Führer" significou a supressão do conflito político (que permitiria alguma instância de controle das decisões do soberano) e, por conseqüência, da forma Direito. Franz Neumann coloca-nos diante de um Estado sem Direito (trata-se também de um não-Estado, como dirá em Behemoth), apontando para a necessidade de seguir o caminho inverso, na direção da raciona lização do Direito material, portanto, da valorização do antagonismo político, sob a forma da Rule of Law.

No exame desse conjunto de instituições, em cujo vértice estão o conflito político e o Estado de Direito - acrescentando-se-lhes a utopia da plena realização do Direito numa sociedade sem classes - talvez possamos encontrar um conceito para a problemática noção de democracia socialista. Ao menos podemos tentar buscar um sentido para as palavras Direito e Democracia que não seja incompatível com a utopia de uma sociedade sem classes.

Resta averiguar em detalhe se essas pistas e indicações de Neumann realmente fazem algum sentido quando colocadas umas ao lado das outras. Mas, mesmo que não seja possível encontrar ligações completamente coerentes entre elas, as inquietações e provocações dos "achados críticos" do autor permanecem incômodas aos olhos da teoria, ainda que não se prestem a fazer sistema. Mas nem só de sistema vive a filosofia.

JOSÉ RODRIGO RODRIGUEZ é doutorando em Filosofia pela Unicamp e pesquisador do Núcleo Direito e Democracia do Cebrap. 